\title{
Recommendations for pacemaker prescription for symptomatic bradycardia
}

\author{
Report of a working party of the British Pacing and Electrophysiology Group
}

Members of working party:

City General Hospital, Stoke-on-Trent Malcolm Clarke

Westminster Hospital, London

Richard Sutton

St George's Hospital,

London

David Ward

St George's Hospital, London

A John Camm

Royal National Heart and Chest Institute,

London

Anthony Rickards

Westminster Hospital,

London

Ann Ingram

Leeds General

Infirmary

E John Perrins

Broadgreen Hospital,

Liverpool

Richard Charles

Royal National Heart

and Chest Institute,

London

Sue Jones

General Infirmary,

Glasgow

Stuart Cobbe

Correspondence to

Dr Malcolm Clarke,

Honorary Secretary, BPEG

Cardiology Department,

City General Hospital,

London Road, Stoke-on-

Trent ST4 6QG.

Accepted for publication

26 February 1991
After the first permanent pacemaker implantation in $1958,{ }^{1}$ the initial developments in pacemaker technology were aimed towards more efficient pacemaker performance. The standard mode of pacing in these early years was single chamber ventricular stimulation and this became established as effective lifesaving therapy. ${ }^{2}$ Over the past 10 years, however, there has been a wealth of different features incorporated into pacemaker design, including programmability, telemetry, and different "modes" of pacing. . $^{3-6}$

The British Pacing and Electrophysiology Group (BPEG) was formed as a specialist subgroup of the British Cardiac Society in 1976 and consists of cardiologists, technicians, and representatives from the pacemaker manufacturing industry. BPEG is organised for the purposes of scientific communication, research, and education specifically related to cardiac pacing and electrophysiology. The group organises an active scientific and educational programme and has more than 200 members.

A working party was formed by BPEG to establish guidelines for the use of the different modes of cardiac pacing. The nomenclature for pacemaker modes accepted for international use is that produced by a combined working party of the North American Society of Pacing and Electrophysiology (NASPE) and the British Pacing and Electrophysiology Group (BPEG) known as the NBG (NASPE/ BPEG generic) code. ${ }^{7}$ This is a code of five letters of which the first three are most often used (table 1). In addition, a fourth letter $R$ is used if adaptive rate pacing is programmed. In adaptive rate (or rate responsive) pacing there is an additional sensor in the pacemaker system that detects a physiological or semiphysiological result of exercise or emotion and increases the pacemaker rate on the basis of a programmable algorithm. Sensors that are presently successfully used in pacemakers include activity, ${ }^{8}$ respiratory rate ${ }^{9}$ and minute ventilation, ${ }^{10}$ right ventricular pressure $(\mathrm{dP} /$ $\mathrm{dt}),{ }^{11}$ central venous temperature, ${ }^{12}$ evoked QT interval, ${ }^{5}$ and oxygen saturation. ${ }^{13}$ Whatever the sensor effective adaptive rate pacing can be used independently of atrial activity. Recently, activity sensing has been combined with dual chamber pacing. ${ }^{6}$

The NBG code also uses a fifth letter relating to antitachycardia function which is not

\section{Table 1 NBG pacemaker code}

FIRST letter signifies the chamber(s) of the heart being PACED

A (atrium)

D (atrium and ventricle)

SECOND letter indicates the chamber(s) being SENSED $\mathrm{A}$ (atrium)

$\begin{array}{ll}\mathrm{V} & \text { (ventricle) } \\ \mathrm{D} & \text { (atrium and ventricle) }\end{array}$

THIRD letter indicates the MODE of sensing

I (inhibited)

$T$ (triggered)

D (inhibited and triggered)

discussed in this document. Each of the pacing modes under discussion is described in the Appendix.

\section{AHA/ACC Guidelines}

Over the past 30 years the clinical indications for pacing have increased to include a large number of different cardiac arrhythmias. To clarify the situation a combined working group of the American Heart Association and the American College of Cardiology has published guidelines on the indications for pacing. ${ }^{14}$ There are three main classes of patients, which may be summarised as follows:

Class I-Conditions in which there is general agreement that permanent pacemakers should be implanted. This includes syncopal patients with complete heart block or prolonged sinus arrest.

Class II-Conditions in which permanent pacemakers are frequently used but there is some divergence of opinion about whether they are needed. Included within this group are the sick sinus syndrome patients without syncope but with other symptoms and also patients with symptomatic incomplete atrioventricular block. Asymptomatic complete heart block is also in this category.

Class III-Conditions in which there is general agreement that pacemakers are not necessary. This includes asymptomatic patients with sinus node disease or first or second degree atrioventricular block and patients with unexplained syncope without obvious cardiac arrhythmia.

\section{BPEG Guidelines}

The AHA/ACC recommendations have 
provided a logical foundation to guide physicians considering cardiac pacing as a treatment for their patients. There are, however, some areas where published data indicate that pacing should be more widely used as a first-line therapy.

Carotid sinus syndrome ${ }^{15}$ and, more recently, malignant vasovagal syncope ${ }^{16}$ would now qualify as firm indications for pacemaker implantation when appropriate investigation shows a major cardioinhibitory effect. ${ }^{1617}$ Furthermore, untreated persistent second degree atrioventricular block, even in asymptomatic patients, has been shown to be associated with a reduced expectation of life. In this group of patients prophylactic pacing restores life expectation to normal. ${ }^{18}$ The Wenckebach phenomenon can occur during sleep in normal individuals with high vagal tone and these people do not need to be considered for treatment. However, those asymptomatic patients with either Wenckebach or Mobitz II second degree atrioventricular block occurring during much of the day and night would qualify for pacemaker implantation, ${ }^{19}$ as would patients with asymptomatic complete heart block. With these modifications, the AHA/ACC guidelines can be used both as a clinical aid and a basis for medical audit of the indications for pacemaker implantation. However, recommendations about the choice of pacemaker prescription are limited.

\section{Choice of pacemaker mode}

When the choice of pacemaker mode for an individual patient is considered, the ideal is production of a paced cardiac rhythm with as many features of normal sinus rhythm as possible (table 2). The guidelines proposed in this paper are based on an attempt to allow the pacemaker response to behave as physiologically as possible. This includes restoration of atrioventricular synchrony and/or rate adaptive pacing wherever needed. To achieve this ideal, detailed information of the underlying cardiac rhythm should be obtained before or during pacemaker implantation. The following features should be considered.

\section{ATRIOVENTRICULAR SYNCHRONY}

Pacemaker systems that maintain atrioventricular synchrony with a physiological atrioventricular interval have been shown to increase cardiac output both at rest and on exercise in patients with normal and impaired left ventricular function. ${ }^{20}$ Even in the absence of an exercise induced rate response, atrioventricular synchrony reduces the number of minor symptoms (dizziness, lethargy) that are associated particularly with sinus node disease. $^{21}$

Table 2 General principles of pacemaker choice

(1) The ventricle should be paced if there is actual or threatened atrioventricular block.

(2) The atrium should be paced/sensed unless contraindicated.

(3) Rate response is not essential if the patient is inactive or has a normal chronotropic response.

(4) Rate hysteresis may be valuable if the bradycardia is intermittent.
RATE MODULATION

Adaptive rate (or rate responsive) pacing significantly increases cardiac output on exercise in patients with atrioventricular block ${ }^{8}$ and sinus node disease. ${ }^{22}$ Patients treated with rate responsive pacemakers achieve higher workloads and greater exercise tolerances. ${ }^{82}$

\section{ATRIAL PACING}

Evidence is accumulating of a considerable reduction in the high spontaneous incidence of the development of atrial fibrillation ${ }^{23}$ and of systemic emboli ${ }^{24}{ }^{25}$ in patients with sinus node disease treated by a pacing system that maintains atrioventricular synchrony.

\section{LEFT VENTRICULAR PERFORMANCE}

Spontaneous (normal) ventricular contraction may allow better ventricular function than a paced ventricular beat. ${ }^{26}$ Typically, the ventricular pacing lead is inserted into the right ventricle and delivery of the pacing stimulus at this site results in the equivalent of left bundle branch block. This causes measurable impairment of left ventricular contraction which may be of haemodynamic relevance in both normal ${ }^{27}$ and compromised left ventricles. ${ }^{28}$

\section{RATE HYSTERESIS}

Hysteresis is a programmed feature whereby the pacemaker paces at a faster rate than the sensing rate. For example, pacing at 80 pulses a minute with a hysteresis rate of 55 means that the pacemaker will be inhibited at all rates down to 55 beats per minute. Having been activated at a rate below 55, the pacemaker then switches on and paces at 80 pulses a minute. Unless careful record is made in the patient's notes that hysteresis has been programmed, pacemaker malfunction could be incorrectly inferred.

\section{ATRIAL ARRHYTHMIAS}

The presence of atrial activity other than chronic or frequently repetitive atrial flutter or fibrillation generally requires an atrial pacemaker electrode. Paroxysmal atrial arrhythmias are not a contraindication to atrial pacing ${ }^{29}$ or sensing in most cases, because atrial pacing may stabilise the atrial rhythm ${ }^{30}$; in others concomitant drug treatment may be beneficial. In those patients with atrial bradycardia and intact atrioventricular conduction, a single chamber atrial pacemaker can be considered to be the treatment of choice. ${ }^{29}$ However, the presence of minor abnormalities of atrioventricular conduction-for example first degree atrioventricular block (PR interval prolongation) or bundle branch disease with normal atrioventricular conduction generally suggests a need for placement of a ventricular lead in patients with symptomatic sinoatrial disorders. ${ }^{31}{ }^{32}$

\section{TYPES OF ARRHYTHMIAS REQUIRING PACING}

Table 3 shows the percentage occurrence of arrhythmias in a typical population of patients with bradycardia requiring pacing. ${ }^{33}$ For the purposes of table 3 , sinus node disease includes 
Table 3 Percentage incidence of various bradyarrhythmias in a typical pacemaker population

\begin{tabular}{ll}
\hline Arrhythmia & $\%$ \\
\hline Sinus node disease & 25 \\
AV block & 42 \\
Sinus node disease + AV block & 10 \\
Atrial fibrillation + AV block & 13 \\
Carotid and vasovagal syndromes & 10 \\
\hline AV, atrioventricular. &
\end{tabular}

sinus bradycardia, sinus arrest, sinoatrial block, and the tachycardia-bradycardia syndome, but does not include atrial bradyarrhythmias associated with carotid sinus syndrome or malignant vasovagal syndrome.

CAROTID SINUS AND MALIGNANT VASOVAGAL SYNDROMES

Carotid sinus syndrome can be diagnosed in a patient with syncope by the presence of a positive carotid sinus massage test. The development of either a period of asystole in excess of three seconds, or the appearance of atrioventricular block, during five to six seconds of firm carotid sinus massage (not compression) is regarded as diagnostic. ${ }^{17}$ The test should not be performed in patients with carotid artery bruits or documented stenosis, after recent myocardial infarction, or if the patient is digitalised. Variations of carotid sinus syndrome include micturition syncope, ${ }^{34}$ cough syncope, ${ }^{35}$ and deglutition syncope. ${ }^{36}$ Malignant vasovagal syncope can be demonstrated by performing a $60^{\circ}$ head-up tilt test. Syncope associated with bradycardia or hypotension or both occurs within 40 minutes. ${ }^{16}$

In patients with carotid sinus and malignant vasovagal syndromes there are two components to the syncope-bradycardia (cardioinhibition) and peripheral and splanchnic vasodilation (vasodepression). In patients with a pronounced vasodepressor effect, pacing is less successful than in patients with a dominant cardioinhibitory effect. ${ }^{15}$ If patients are suitable

Table 4 Recommended pacemaker modes

\begin{tabular}{llll}
\hline Diagnosis & Optimal & Alternative & Inappropriate \\
\hline SND & AAIR & AAI & VVI \\
& & & VDD \\
AVB & DDD & VDD & AAI \\
& & & DDI \\
SND and AVB & DDDR & DDD & AAI \\
& DDIR & DDI & VVI \\
Chronic AF & VVIR & VVI & AAI \\
with AVB & & & DDD \\
& & & VDD \\
CSS & DDI & DDD & AAI \\
& & VVI & VDD \\
MVVS & DDI & DDD & AAI \\
& & & VVI $\dagger$ \\
& & & VDD
\end{tabular}

The optimal mode of pacing should be considered for most patients. The alternative mode should be regarded as being less satisfactory, but acceptable in some groups of patientsfor example those who are disabled by another disease, those with very intermittent symptoms, or those who have a short life expectancy because of another disease. When a patient with, for example, a previous hemiplegia or with terminal neoplasia has atrioventricular block, VVI may suffice to reduce symptoms.

symptoms. syndrome rate hysteresis is recommended. ${ }^{38}$ Patient selection should follow the guidelines suggested by Brignole et al. ${ }^{39}$

†See reference. ${ }^{40}$ gVide AVVS, malignant vasovagal syndrome; SND, sinoatrial node disease; CSS, carotid sinus syndrome. for pacing the mode of choice for carotid sinus syndrome and malignant vasovagal syndrome is $\mathrm{DDI},{ }^{37}$ frequently with hysteresis as an added feature. ${ }^{38}$

\section{ATRIAL TRACKING PACING SYSTEMS}

It is recognised that the pacing system known universally as DDD behaves for most of the time as a VDD system. The only difference is the behaviour at the lower programmed rate, where the DDD paces into the atrium and the VDD has a back-up VVI mode. For the patient with bradycardia that is slower than the lower programmed rate, this may have significant disadvantages including pacemaker syndrome. In sinus node disease the potential benefit of pacing the atria is not available in VDD mode.

Table 4 shows the recommended modes, based on these principles, for patients with all varieties of bradyarrhythmias requiring pacing.

\section{Complications of inappropriate mode selection}

Inappropriate pacemaker modes (table 4) should be avoided to prevent the following complications:

(a) Pacemaker syndrome, ${ }^{41}$ which is caused either by retrograde conduction from the ventricle to the atrium or by lack of synchronous atrioventricular activity that results in loss of atrial transport function. Pacemaker syndrome may cause symptoms of syncope or pre-syncope as a result of retrograde conduction. ${ }^{41}$ Dyspnoea may occur where there is high pulmonary venous pressure and low cardiac output and associated mitral regurgitation (demonstrable by Doppler echocardiography) caused by a lack of atrioventricular synchrony. ${ }^{42}$ Neck pulsation may be seen when retrograde atrioventricular conduction causes tricuspid regurgitation or right atrial contraction against a closed tricuspid valve. The true incidence of pacemaker syndrome is not well defined but it is thought that $10 \%$ of patients paced VVI have quite severe symptoms and another $15 \%$ have a reduced quality of life as a result. ${ }^{41}$ All these symptoms can be relieved by a more appropriate pacing mode.

(b) Inappropriate atrial tracking of atrial tachyarrhythmias by a DDD or VDD system..$^{43}$ Atrial tachycardia, flutter, or fibrillation produce an electrogram which can be easily detected by the atrial sensing amplifier of the pacemaker, which will then track this rhythm at its upper pacing rate. Newer dual chamber rate adaptive systems incorporate algorithms that prevent or minimise inappropriate ventricular pacing in response to atrial fibrillation.

(c) Additional atrioventricular block in a patient with sinus node dysfunction may not be easily detected initially. ${ }^{44}$ Normal $1: 1$ atrioventricular conduction at atrial pacing at rates of 140 usually indicates adequate atrioventricular nodal function. The appearance of the atrioventricular Wenckebach block at slower rates may be considered indicative of important impairment of atrioventricular node conduction which warrants placement of a ventricular 
lead. There may be other evidence of inadequate atrioventricular conduction from Holter monitoring, exercise stress testing, or His bundle electrography.

(d) Lack of physiological heart rate response on exercise. Unrecognised sinus node dysfunction in a patient with atrioventricular block would result in inadequate performance of an atrial tracking (DDD) pacemaker. In addition, there are some patients with sinus node disease treated by atrial rate modulated pacing systems who may develop abnormal atrioventricular conduction on exercise $e^{45}$ resulting in an unusual variety of pacemaker syndrome.

\section{Additional guidelines}

The following additional guidelines are recommended to enable accurate assessment of a patient requiring pacemaker implantation:

(a) In selected patients atrioventricular conduction should be assessed by Holter, carotid sinus massage, and atrial pacing to assess the atrioventricular Wenckebach point at the time of implant if atrial pacing (AAI) is being considered.

(b) Retrograde atrioventricular conduction should be assessed by ventricular pacing if VVI or VVIR pacing is considered. Head-up tilting during ventricular pacing may reveal latent symptoms.

(c) If VDD or DDD pacing is being considered in active patients the chronotropic response of the sinus node should be assessed by Holter or exercise testing. If the response is inadequate an appropriate sensor driven system may be needed.

\section{Consequences of increased use of dual chamber and rate responsive pacing cost}

A VVIR unit costs about $40-50 \%$ more and a dual chamber unit costs $40-100 \%$ more than a multiprogrammable single chamber pacemaker. In addition, a dual chamber system requires two pacing leads which further increase the cost. Rate-responsive pacing systems have a shorter battery lifetime than nonrate responsive modes because of their overall faster pacing rate and the inherent current drain of the sensor.

However, pacing is cost effective in terms of relief of symptoms, prolongation of life, and improvement of the quality of life. ${ }^{2046-50}$ Patients with pacemakers rarely need to be readmitted to hospital because of problems. So a tailored pacemaker prescription that follows the guidelines in this report will offer good value for money.

\section{FOLLOW UP}

Patient follow up with VVIR and dual chamber systems is initially more complex and time consuming. Additional programming is necessary together with Holter taping and exercise testing where required. Support staff need to be trained. When the pacing system has been "fine tuned" to the individual patient's requirements, however, subsequent follow up is less time consuming.

\section{COMPLICATIONS}

Complex pacing systems are more susceptible to problems. Dual chamber systems require two endocardial leads and lead related complications are therefore slightly increased. ${ }^{51}$ Inappropriate programming may also give rise to difficulties. A badly programmed sensor may give excessive or inadequate rate responses. It is possible to select an inappropriate sensor system for an individual patient-for example, an activity sensor in a bedbound patient or a minute-ventilation sensor in a patient with chronic lung disease are as inappropriate as a DDD system would be in a patient with atrial flutter.

Which hospitals should implant and follow up pacemakers?

Over recent years, it has been the policy of some regional health authorities to encourage pacemaker implantation in district general hospitals. This is acceptable but it demands at least one cardiologist fully trained in the complex disciplines of dual chamber pacing and follow up, together with at least one similarly trained physiological measurement technician. Hospitals with only one cardiologist would need to make arrangements with similarly trained staff in a neighbouring district to cover periods of absence.

\section{Choice of pacing system}

When choosing a pacemaker system for a patient, a physician usually adopts one of three policies:

(a) A basic VVI system for everyone, irrespective of need, symptoms, or electrocardiographic findings. This policy is clearly inappropriate.

(b) The routine use of the most sophisticated dual chamber rate adaptive pacemaker (DDDR) for every patient, programmed to match the patients' needs. This is medically acceptable, but inappropriate on grounds of cost.

(c) A device that is carefully prescribed according to the guidelines in this report. This again is medically sound, but this policy requires thorough assessment of the patient before pacemaker implantation and meticulous follow up.

This working party of BPEG recommends that selection of the appropriate pacemaker mode should follow the basic principles and guidelines discussed above. This will require a fairly radical change of practice in some pacemaker centres in the United Kingdom and additional funding for the more complex pacemaker systems and their subsequent follow up.

1 Elmqvist R, Senning A. An implantable pacemaker for the heart. Smyth CN, ed. In: Medical electronics. Proceedings of the second international conference on medical electronics. London: Illife, 1959:253.

2 Ginks W, Leatham A, Siddons H. Prognosis of patients paced for chronic atrioventricular block. Br Heart J 1979;41:633-6.

3 Sutton R, Citron P, Perrins J. Physiological cardiac pacing. PACE 1980;3:207-17. 
4 Clarke M, Allen A. Use of telemetered electrograms in the assessment of normal pacemaker function. $J$ Electrophysio 1987;1:388-95.

5 Rickards AF, Norman J. Relation between QT interval and heart rate. New design of a physiologically adaptive cardiac pacemaker. Br Heart J 1981;45:56-61.

6 Kappenberger L, Hepers L. Rate responsive dual chamber pacing. PACE 1986;9:987-91.

7 Bernstein A, Camm J, Fletcher R, et al. The NASPE/BPEG generic pacing code for antibradyarrhythmia and adaptive rate pacing and antitachycardia devices. PACE 1987; 10:794-9.

8 Humen D, Anderson K, Brumwell D, Huntley S, Klein G. A pacemaker which automatically increases its rate with physical activity. In: Steinbach $\mathrm{K}$, Glogard A, Laszkovicsa D, Schneibelhofer W, Weber H, eds. Cardiac pacing. Darmstadt: Steinkopff Verlag, 1983:252-64.

9 Rossi P, Plicchi G, Canducci G, Rognoni G, Aina F Respiration as a reliable physiological sensor for controlling cardiac pacing rate. Br Heart J 1984;51:7-14

10 Lau C, Antoniou A, Ward D, Camm AJ. Reliability of minute ventilation as a parameter for rate responsive pacing. $P A C E$ 1989;12:321-30

11 Sutton $R$, Sharma $A$, Ingram A, Camm J, Lindemans $F$, Bennett T. First derivative of right ventricular pressure as a sensor for an implantable rate responsive VVI pacemaker [abstract]. PACE 1988;11:487.

12 Alt E, Völker R, Högl B, MacCarter D. First clinical results with a new temperature-controlled rate responsive pacemaker. Circulation 1988;78 (suppl III):116-24.

13 Stangl K, Wirtzfeld A, Heinze R, Laule M. First clinical experience with an oxygen saturation controlled experience with an oxygen saturation

14 Frye RL, Collins JJ, DeSanctis RW, et al. Guidelines for permanant pacemaker implantation-May 1984. A report
of the joint American College of Cardiology/American of the joint American College of Cardiology/American Heart Association Task Force on assessment of Car-
diovascular Procedures (Subcommittee on Pacemaker diovascular Procedures (Subcommittee on Pacem

15 Morley CA, Perrins EJ, Grant P, Chan SL, McBrien DJ, Sutton $R$. Carotid sinus syncope treated by pacing. Analysis of persistent symptoms and role of atrioventricular sequential pacing. Br Heart $J$ 1982;47:411-8.

16 Fitzpatrick A, Sutton R. Tilting towards a diagnosis in recurrent unexplained syncope. Lancet 1988;i:658-60.

17 Morley C, Sutton R. Carotid sinus syndrome-editorial review. Int J Cardiol 1984;6:287-93.

18 Shaw D, Kekwick C, Veale D, Gowers J, Whistance T. Survival in second degree atrioventricular block. $\mathrm{Br}$ Heart $J$ 1985;53:587-93.

19 Campbell RWF. Chronic Mobitz type I second degree atrioventicular block. Has its importance been underestimated? Br Heart J 1985;53:585-6.

20 Kruse I, Arnman K, Conradson T, Ryden L. A comparison of the acute and long-term haemodynamic effects of ventricular inhibited and atrial synchronous ventricular ventricular inhibited and atrial synchronous

21 Mitsuoka T, Kenny RA, Yeung TA, Chan SL, Perrins JE, Sutton R. Benefits of dual chamber pacing in sick sinus syndrome. Br Heart $J$ 1988;60:338-47.

22 Rognoni G, Bolognese L, Aina F, Occhetta E, Magnani A, Rossi P. Respiratory dependant atrial pacing, management of sinus node disease. PACE 1988;11:1853-9.

23 Rosenqvist M, Brandt J, Schuller $H$. Long-term pacing in sinus node disease; effects of stimulation mode on cardiovascular morbidity and mortality. Am Heart $J$ 1988;116:16-22.

24 Santini M, Alexidou G, Porto M, Santini A, Ammirati F, Ansalone G. The sick sinus syndrome: prognosis as function of age, conduction defects and pacing mode [abstract]. PACE 1989;12:1237.

25 Bianconi L, Boccadamo R, Di Florio A, et al. Atrial versus ventricular stimulation in sick sinus syndrome; effects on morbidity and mortality [abstract]. PACE 1989;12:1236.

26 Theodorakis G, Fitzpatrick A, Ahmed R, Travill C, Sutton $R$. Doppler estimation of cardiac output during AAI and DDD pacing (with varying AV delay) at different pacing rates [abstract]. $P A C E$ 1989;12:1185.

27 DeNardo D, Antolini M, Pitucco O, et al. Effects of left bundle branch block on left ventricular function in apparently normal subjects. Cardiology 1988;75:365-71.

28 Gibson DG, Chamberlain DA, Coltart DJ, Mercer J. Effect dynamics in man. Comparison of right ventricular, left ventricular, and simultaneous pacing of both ventricles. Br Heart J 1971;33:397-400.

29 Ryden L. Atrial inhibited pacing - an underused mode of cardiac stimulation. PACE 1988;11:1375-9.

30 Egobasti A, Gueunoun M, Sasdjian A, et al. Long-term follow-up of patients treated with VVI pacing and sequential pacing with special reference to VA retrograde conduction. PACE 1988;11:1929-34.

31 Sutton R, Kenny R. Natural history of sick sinus syndrome. PACE 1986;9:1110-4.

32 Rosenqvist M, Obel I. Atrial pacing and the risk for AV block: Is there a time for change of attitude? $P A C E$ 1989;12:97-101.

33 British Pacing and Electrophysiology Group Databasestatistics for the City General Hospital, Stoke-on-Trent, 1986-1989.

34 Haldane JH. Micturition syncope. Can Med Assoc J 1969; 101:712-4.

35 Hart G, Oldershaw P, Cull R, Humphrey P, Ward D. Syncope caused by cough-induced complete atrioventricular block. $P A C E$ 1982;5:564-66.

36 Igaluer S, Swartz B. Heart block periodically induced by the swallowing of food in a patient with cardiospasm (vasovagal syncope). Ann Otol Rhinol Laryngol 1936; 45:875-81.

37 Sutton R, Ingram A, Clarke M. DDI pacing in the treatment of sick sinus, carotid sinus and vasovagal syndromes [abstract]. PACE 1988;11:827.

38 Morley C, Perrins EJ, Chan SL, Sutton R. The role of rate hysteresis pacing in the hypersensitive carotid sinus syndrome. PACE 1983;6:1224-8.

39 Brignole M, Menozzi C, Lolli G, Oddone D, Roti S. When is DDD pacing necessary and when is VVI pacing sufficient in carotid sinus syndrome? [abstract]. PACE 1989; 12:1169.

40 Fitzpatrick AP, Travill CM, Vardas PE, et al. Recurrent symptoms after ventricular pacing in unexplained synsymptoms after ventricular pac
cope. $P A C E$ 1990;13:619-24.

41 Ausubel K, Furman S. The pacemaker syndrome. Ann Intern Med 1985;103:420-9

42 Naito M, Dreyfus L, David D, Nicholson E, Mardela T, Kmetzo J. Re-evaluation of the role of atrial systole in cardiac hemodynamics: evidence for pulmonary venous regurgitation during abnormal atrioventricular sequencing. Am Heart $J 1983 ; 105: 295-302$.

43 Castellanos A, Lemberg L, Rodriquez-Tocker L, et al. Atrial synchronised pacemaker arrhythmias, revisited. Am Heart J 1968;76:199-205.

44 Steinbach K, Forohner K, Meisl F, et al. Atrial stimulation In: Pérez Gómez F, ed. Cardiac pacing. Madrid: Grouz, 1985:629.

45 Clarke $M$, Allen A. Rate responsive atrial pacing resulting in pacemaker syndrome [abstract]. PACE 1987;10:1209.

46 Perrins JE, Morley CA, Chan SL, Sutton R. Randomised controlled trial of physiological and ventricular pacing. $\mathrm{Br}$ Controlled trial of phys $J$ 1983;50:112-7.

47 Lau CP, Rushby J, Leigh-Jones $M$, et al. A double blind cross-over study on the symptomatology and quality of life in patients with rate responsive pacemakers [abstract]. in patients with rate responsive

48 Fitzgerald WR, Graham IM, Cole T, Evans DW. Age, sex and ischaemic heart disease as prognostic indicators in

49 Edhag O, Swann A. Prognosis of patients with complete heart block or arrhythmic syncope who were not treated by cardiac pacemakers. Acta Med Scand 1976;200:457-63.

50 Williams A. Economics of coronary artery bypass grafting. $B M J$ 1985;291:326-9.

51 Sutton $\mathrm{R}$, Ingram A, Briers $\mathrm{L}$, et al. Ten years of physiological cardiac pacing. In: Belhassen B, Feldman S Copperman Y, eds. Cardiac pacing and electrophysiology. Jerusalem: R \& L Creative Communications, 1987:141-2.

52 Cunningham T. Pacemaker syndrome due to retrograde conduction in DDI pacemaker. Am Heart $J$ 1988; 115:478-9.

53 Ricci D, Rider A, Mason J. Recurrent tachyarrhythmia associated with a bifocal demand pacemaker. Chest 1977 72:120-3.

54 Den Dulk K, Lindemans FW, Banf W, et al. Pacemaker related tachycardia. $P A C E$ 1982;5:476-85.

55 Torresani J, Egobasti A, Allard-Latour G. Pacemake syndrome with DDD pacing. $P A C E$ 1984;7:1148-51. 